\title{
GEOGRAPHY, HISTORY AND NATURAL SCIENCES: AN INTERDISCIPLINARY TEACHING APPROACH WITH GIS
}

\author{
V. Ribeiro ${ }^{1,2}$, I.B.C.Monteiro ${ }^{1}$, M. Quinta e Costa ${ }^{1}$ \\ 1 ESEPF, CIPAF (PORTUGAL) \\ ${ }^{2}$ Minho University, Lab2PT (PORTUGAL)
}

\begin{abstract}
Geographic Information System (GIS) is a technology that deals with location to support better representations and decision making. It has a long tradition in several planning areas, such as urbanism, environment, riskiness, transportation, archeology or tourism. In academics context higher education has followed that evolution. Despite of their potentialities in education, GIS technologies at the elementary and secondary have been underused. Empowering graduates to learn with GIS and to manipulate spatial data can effectively facilitate the teaching of critical thinking. Likewise it has been recognized that GIS tools can be incorporated as an interdisciplinary pedagogical tool. Nevertheless more practical examples on how GIS tools can enhance teaching and learning process, namely to promote interdisciplinary approaches. The proposed paper presents some results obtained from the project "Each thing in its place: the science in time and space". This project results from the effort of three professors of Geography, History and Natural Sciences in the context of Didactics of World Knowledge curricular unit to enhance interdisciplinarity through Geographic Information Technologies (GIT). Implemented during the last three years this action-research project developed the research practice using GIS to create an interdisciplinary attitude in the future primary education teachers. More than teaching GIS the authors were focused on teaching with GIS to create an integrated vision where spatial data representation linked the space, the time and natural sciences. Accumulated experience reveals that those technologies can motivate students to learn and facilitating teacher's interdisciplinary work.
\end{abstract}

Keywords: Geographical Information System (GIS), Interdisciplinary, Teaching and Learning, Geography, History, Natural Sciences, Pedagogical tool.

\section{INTRODUCTION}

Technology is playing an important role for the XXI century education. The unprecedented growing of technology in our day life's [1], in line with this Geographic Information Systems (GIS) technology and associated methods simplified the decision-making process [2]. A better internet service opens new teaching horizons by simplifying the management, manipulation, sharing and implementation of geographic databases, for example, through story map making. In this information age schools are challenged to adapt their curricula to improve skills, develop new strategies and harvest motivating resources. GIS tools facilitate spatial visualization of geographical data throw space and time representations.

It is recognized that GIS is an interdisciplinary tool despite "has not been pedagogically integrated at the program level" [3]. Nowadays students should be prepared to solve problems. Due to the complex and fast changing reality of our society, interdisciplinary education is required rather than looking to a problem by one length or field [2]. Indeed GIS helps students and teachers to take advantage of this multiplicity and variety of data to think on a holistic manner to think critically and solve problems. Also teachers need to enlarge the knowledge of how to explore the content, pedagogy and technology together [4, 5]. In fact, for using GIS and capture more potentialities' an integrated pedagogy should be adopted to promote an interdisciplinary approach. Here technology is the bridge to reach the knowledge. Teachers should understand how to use it appropriately to capture the variety of research fields' perspectives.

As a hinged discipline, Geography and, particularly, spatial data can bring together, History, Natural Sciences, Archaeology, Mathematical, Language, Biology, among others educational fields. In fact, location is one of the oldest competences of geographical teaching which is crucial for kids to understand the context and to argue about the vision they have about the world $[6,7]$. To develop geographical skills has been recognized that GIS is the main technology to reach it $[2,8-10]$. 
In general approaches, GIS is used to understand the geographic characteristics of the phenomena, namely the changing characteristics over the place where they occur and over time [10]. In the context of the Portuguese primary education the World Knowledge discipline embrace Geography, History and Natural Sciences subjects. Indeed promoting an interdisciplinary teaching can make students having a whole vision of the phenomena, understanding paths and patterns over the space and time. Due to this, we have implemented in the teacher training degree a project to fulfil those aims. GIS Technology was used to represent, about each biographee, the space they lived and moved around. Biography is an important education tool because it is a "valuable resource for teaching historical thinking skills" [11] Instead of the memorization of facts, students can engage in contextualizing from a close reading of primary and secondary sources. Besides that, biography humanizes history, showing how political structures, intellectual and scientific movements and social/economic developments affect people's life in the past as in the present.

\section{INTERDISCIPLINARY APPROACH TROUGH GIS PROJECT}

\subsection{Methodology}

The project "Each thing in its place: the science in time and space" was implemented by Geography, History and Natural Sciences teachers to improve students' interdisciplinary conscience. To that, we selected some scientific personalities and challenged students to study their biography, the scientific area they stood out and the main geographic places the personality have crossed during their life (Fig. 1). After that students should manipulate a geographic database to represent geographic path of each personality using several Geographic Information Technologies, such as virtual globes or ArcGIS, to manipulate geodatabase and produce a static map at different scales and, finally, using internet web map to share a story map. Students were organized by groups of three or four elements. Each group had analysed the biography of one Portuguese personality chosen by them or proposed by professors. The same personality was studied for two students groups of two different classes from the same year. This organization was decided to calibrate eventual difficulties felt by students to find the information for each personality. On the other hand, a different group of personalities in each year prevents the utilization of the information already searched by other group. Personalities were chosen attending to some criteria: to have Portuguese nationality, to be a Portuguese or international reference in a scientific context and to have lived between 19th and 21st century.

The information about the biographees should be searched on printed sources - as books, magazines and journals -, online databases and official webpages of personalities, among others. Students should carefully gather the information and maintain all the interdisciplinary vision during the research work. During the information collection phase about the historic and/or scientific relevance of the personality, they should also contextualize him in time and space. After that, students had to produce a written document with about twenty pages and to do an oral presentation. They had also to organize the information in a poster to be applied as a pedagogic resource on primary school.

Over the three years, we analyse the documents produced by students according to the project goals. The first approach, at the end of the first year, was a preliminary study to evaluate, from the results, the project potential to develop students' research skills and to understand their interdisciplinarity concepts. We have concluded that the students needed more specific orientation to do their research. First, intentionally we didn't give specific orientation - the project methodology and goals were presented and the students performed the research without our supervision. In our preliminary study, we realised that some students collect all the information about a personality and organize it by contents without the interdisciplinary vision, one of the main objectives of the project. This difficulty was minimised by a direct orientation.

Then, a reflexive analyse of the written documents at the end of the first two years of the project implementation allowed us to evaluate the research practices developed by students and their interdisciplinary concepts [12]. At the same time, we evaluated how they worked the didactic transposition by the analysis of the posters. The development of geographic skills were analysed by comparing the information present on the written documents, during the oral presentation of the biographies and by the organization of the posters' information. Project has been developed for three years with biographic studies of thirty distinct personalities (ten in each year). The relative distribution of lifetime of personalities is presented in a chronologic timeline (Fig. 1). 


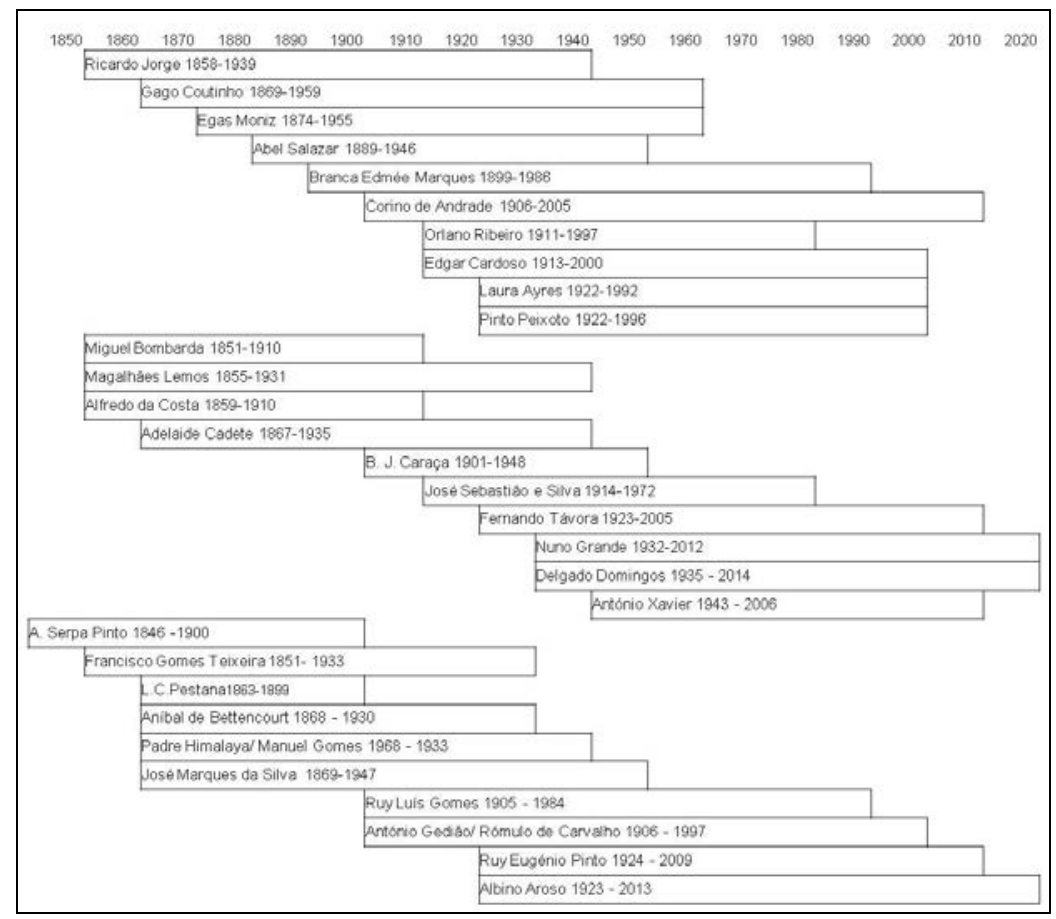

Fig. 1: Scientific person's studied by time.

\subsection{Results}

The project was an opportunity for students to develop research skills. The interdisciplinary approach was not easy for all the students groups. Some of them collected all the information about one personality and organized it by contents. But, more than collect information about History, Natural Science or Geography to be used in each scientific perspective, they had to understand how to connect all the information to reach a more holistic and integrated perspective. They explored Geographic Information Technologies potential to serve an interdisciplinary approach.

Other students demonstrated they understand the potential of the interdisciplinarity and they write about their intention to use this methodology as future teachers of primary classes [13].

With this project, the students acquire skills on how to create a map, the map elements and necessary cartographic option. They understand how subjective is a map and different scales require different cartographic strategies to turn readable the information. Yet it was also possible to explore different base maps from topographic to satellite images and identify the most common errors in geolocation process.

We previously published results from the reflexive analysis from one class at the end of the first two years of project implementation [12]. Now we collect information from the two classes work along the three years of project implementation. This comparative analysis between the two students groups that worked the same biography allows us to minimize uncontrollable effects as individual previous skills of each group element.

We analysed the maps produced by students. On the first year, seventeen groups organized the geographic information presenting static maps produced with the ArcGis software (six groups) or using the Google Earth application (seven groups) or both possibilities (four groups). Four groups presented the information in story map using ArcGis software or virtual globes. Two of them didn't produce static maps. Professors' supervision was organized in modules. The Geography module was the second one, between History and Natural Sciences.

On the second year of the project implementation, the Geography module was the last one because we knew by the students that they need more time to find information they need to produce the maps and to organize it. We verified that a higher number of groups acquired skills to create a static map. The ArcGis software was used by fifteen groups and only two groups used Google Earth. Two groups presented both strategies but none produced a story map. Students had enough time to find 
information and organize it in a static map but they didn't have skills to the organization of a story map. At this time we understood that students need a practical contact with the geographic representation earlier in their higher education on other courses in previous years with the professor of Geography. This previously contact with the GIS technologies could be the explanation to the better results on the third year of the project implementation. Eight groups performed story maps with ArcGis software or Google Earth. As we already mentioning only four groups on first year and none on the second used this technology. Fifteen groups created a static map with ArcGis Software and eight groups used the Google Earth. Five of them represent the geographical movement of personality by both approaches. This year the Geography module was the second in a class and the last in the other. The geographic representation was similar in both classes.

The example showed in fig. 2 is related with Manuel António Gomes who was a relevant Portuguese personality in the field of the renewable energy, namely, the solar energy. In the map the students highlight the presence of the scientist abroad, namely in France (Paris). A cluster is represented in Portugal where he was born but it is not so clear at this scale.

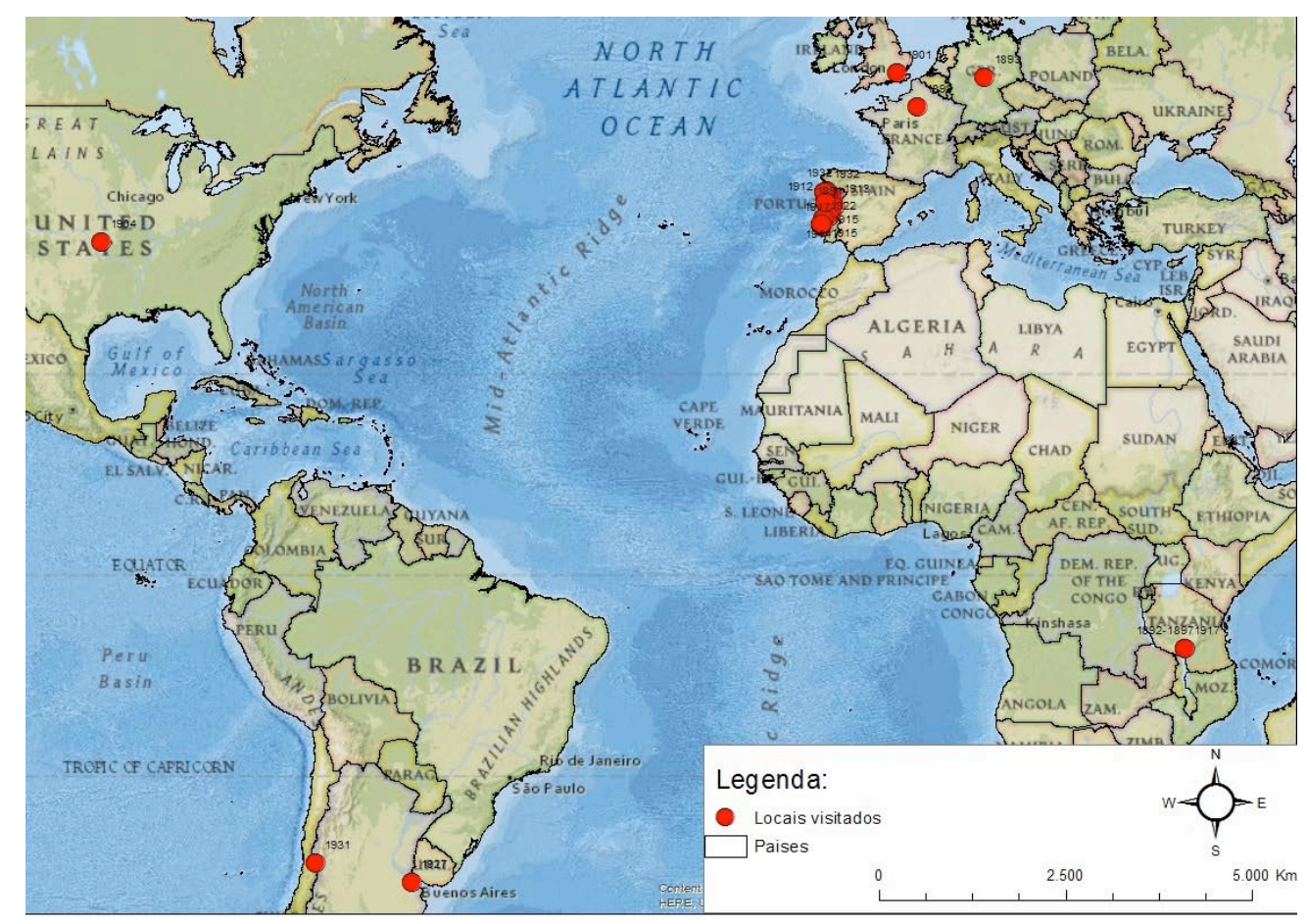

Fig. 2: Geographic map created by a student's group related to the Manuel António Gomes (Father Himalaya nickname) biography.

To show how this personality moved geographically along his life, students decided to share a greater scale map that clearly highlight the main presence in the North and Centre region of Portugal, particularly around the capital: Lisbon (Fig. 3). Thirty groups used this strategy and presented maps at different scales. The number of groups that produced a greater scale map decreases on second year but it increase on third year. 


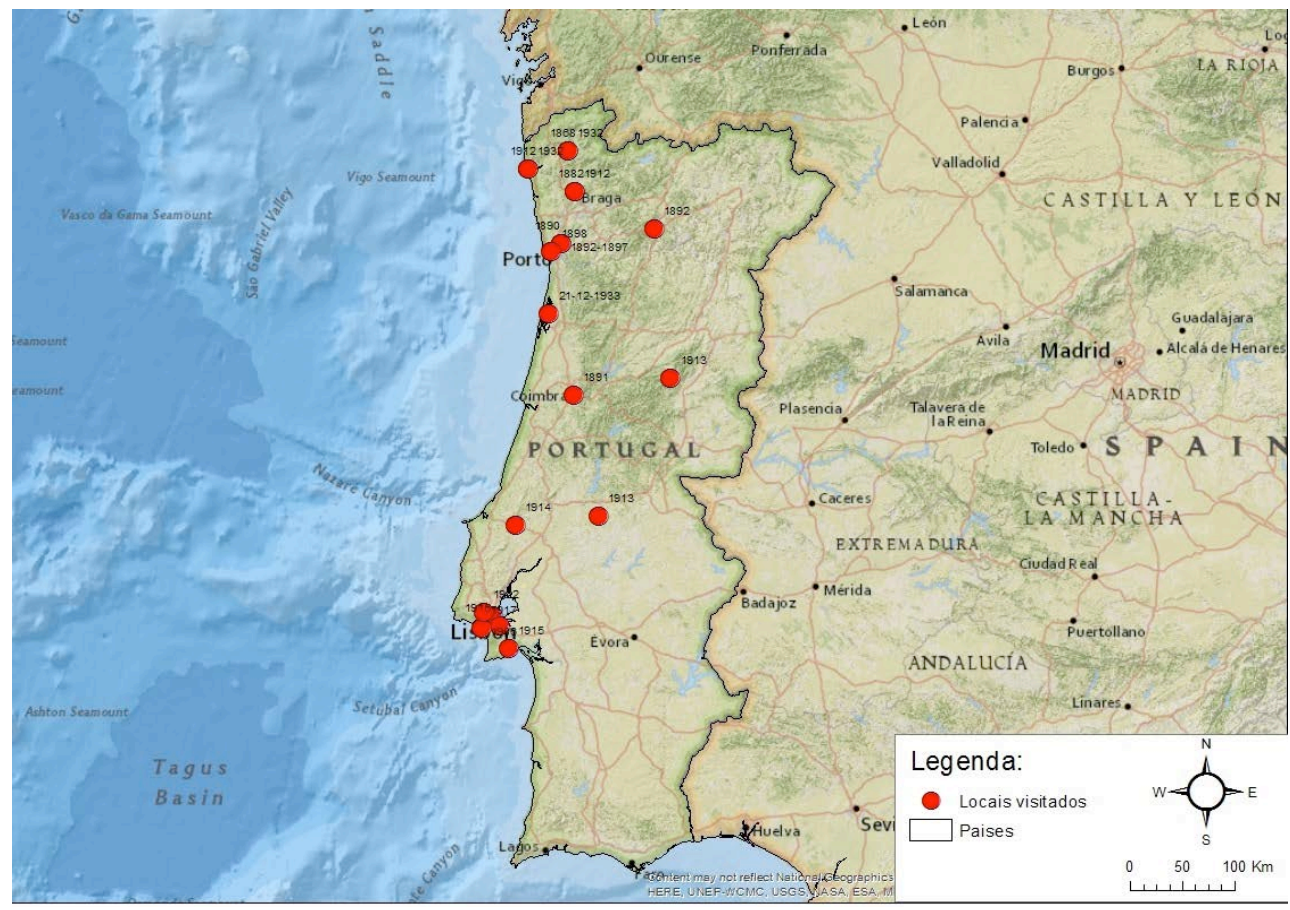

Fig. 3: A greater scale map to show Portugal path of Manuel António Gomes by date.

To preserve memory and local identity several municipalities give to their streets the name of prominent local personalities. To think critically about this, students look up for places those preserve the memory of the studied personality. To show those evidences a local map was produced (Fig. 4). All groups investigate tributes to the personality they studied but fourteen groups represented them by a local map. Local representation was also more valued in the last year of the project.

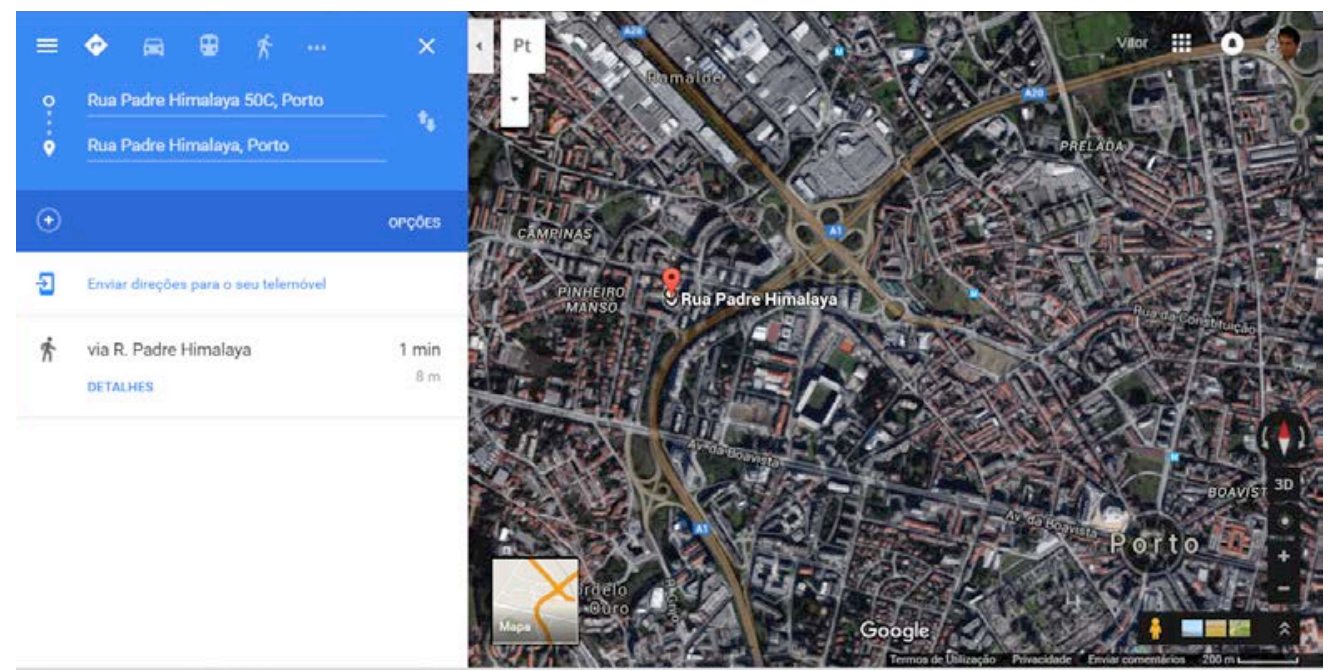

Fig. 4: Local map showing the presence of Father Himalaya in the local memory.

Due to the growing of web mapping students were challenged to produce a story map, shifting from a static map to a dynamic one. Some groups reached this aim as shown in the fig. 5. Several pedagogical tools were integrated in one. Timelines, schemes, pictures, videos and text were combined with a dynamic map, where each symbol had its attribute field visible. This new dimension of presenting the information takes advantage of the web improvements, namely the web mapping. 


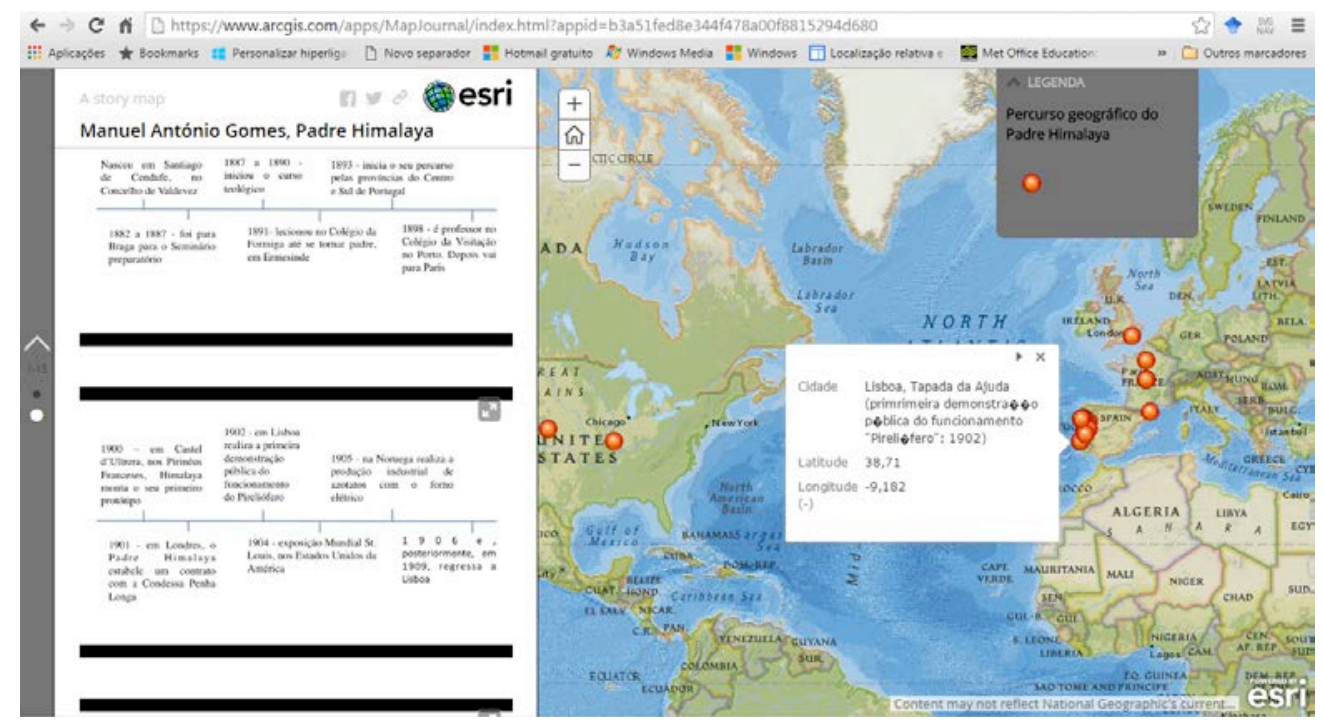

Fig. 5: Story map of Himalaya personality.

The final challenge was related with scientific communication skill improvement. Besides the paper that each group should produce highlighting the interdisciplinary vision through the Geography, History and Natural Sciences context, a poster should be produced (Fig. 6). This final challenge allowed to obtain a poster exhibition that could later be used as a didactic resource, exposed in a primary or secondary school. All the elements obtained for each subject was combined and smoothed to convey a holistic vision of the personality importance. Due to this, students had to choose and synthesise the information of the three main areas in a clear and readable poster.

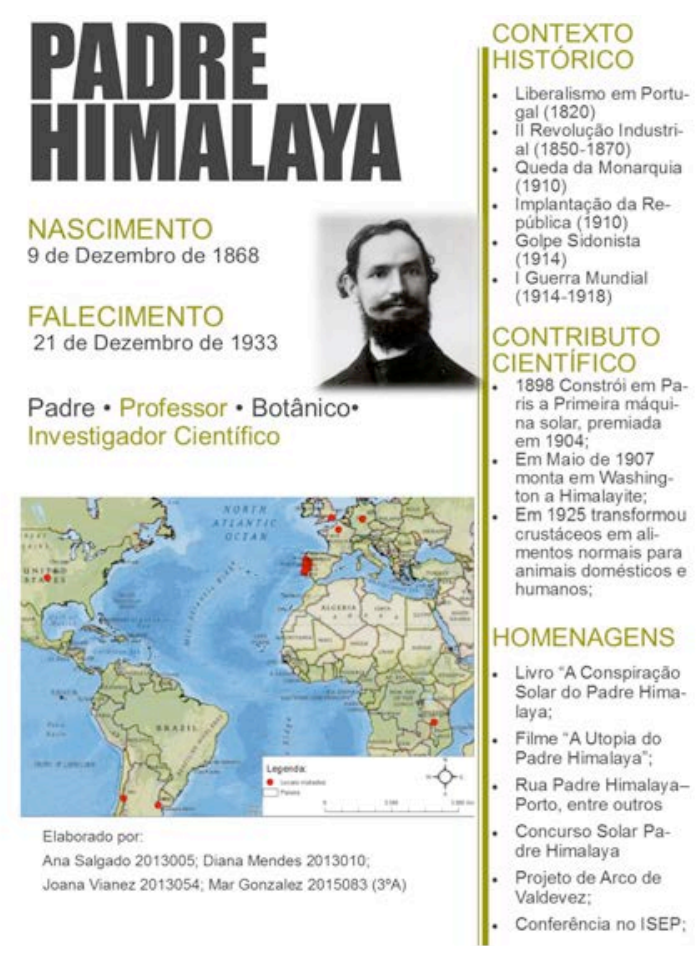

Fig. 6: The final Poster of Himalaya personality.

\section{CONCLUSIONS}

An earlier contact with the geographic representation by the students on other curricular units was positive to the development of the geographical skills. If they are familiarised with GIS tools, they can more easily apply the technology in the biography. However, students developed with this project how to manipulate geodata to produce a static and dynamic maps in context, that is, to achieve the 
objectives proposed by teachers. They refine their critical thinking skills with the interdisciplinary approach.

Our results showed that students understood that geographical representation is an important resource to promote the interdisciplinarity and they claim the intention of use it as future primary teachers. This project promotes research skills in the students, develops, in a practical manner; an interdisciplinary attitude with a different approach to understanding the knowledge; promote the use of the geospatial technologies, aspects that will have repercussions on their future professional practice.

\section{REFERENCES}

[1] Akinyemi, F.O., 2016. Technology use in Rwandan secondary schools: an assessment of teachers' attitudes towards geographic information systems (GIS). International Research in Geographical and Environmental Education, 25(1): p. 20-35.

[2] Kerski, J.J. (2003). The implementation and effectiveness of geographic information systems technology and methods in secondary education. Journal of Geography, 2003. 102(3): p. 128137.

[3] Ferrandino, J. (2014). Incorporating GIS as an Interdisciplinary Pedagogical Tool Throughout an MPA Program. Journal of Public Affairs Education. 20(4): p. 529-544.

[4] Mishra, P. and M. Koehler (2006). Technological pedagogical content knowledge: A framework for teacher knowledge. The Teachers College Record. 108(6): p. 1017-1054.

[5] Kerski, J.J., A. Demirci, and A.J. Milson (2013). The global landscape of GIS in secondary education. Journal of Geography. 112(6): p. 232-247.

[6] Catling, S. (2014). Giving younger children voice in primary geography: empowering pedagogya personal perspective. International Research in Geographical and Environmental Education. 23(4): p. 350-372.

[7] Reynolds, R. and M. Vinterek (2016). Geographical locational knowledge as an indicator of children's views of the world: research from Sweden and Australia. International Research in Geographical and Environmental Education. 25(1): p. 68-83.

[8] Kerski, J. (2015). Opportunities and Challenges in Using Geospatial Technologies for Education, in Geospatial Technologies and Geography Education in a Changing World, $\mathrm{O}$. Muñiz Solari, A. Demirci, and J. Schee, Editors, Springer, Japan. p. 183-194.

[9] Baker, T.R., et al. (2012). Call for an agenda and center for GIS education research. Review of International Geographical Education Online, 2(3): p. 254-288.

[10] Ribeiro, V., I.B. Monteiro, I.B.C. and Quinta e Costa, M. (2016). As Tecnologias de Informação geográfica na Formação de professores - abordagem interdisciplinar com a História e as Ciências Naturais in IV Congreso Internacional Fenda Dixital: TIC, NEE, Inclusão e Equidade. Santiago da Compostela, Espanha: SIPS.

[11] Schmitz, I. (2014). Biography in the History classrrom: chalenges and applications. Bulletin of the GHI, 55, p. 91-101.

[12] Quinta e Costa, M.; Ribeiro, V. and Monteiro, I. (2015). A promoção da atitude interdisciplinar: um projeto de investigação in Atas do I Seminário Internacional Educação, Territórios e Desenvolvimento Humano. Porto: Universidade Católica, II, p. 779-789.

[13] Qui9nta e Costa, M; Monteiro, I. and Ribeiro, V. (2014). Análise reflexiva de uma experiência pedagógica interdisciplinar" in Atas do XII Congresso SPCE, Ciências da Educação: espaços de investigação, reflexão e ação interdisciplinar, p. 1274-1280. 